\title{
FREE FATTY ACIDS IN AN ANIMAL MODEL OF REYE'S SYNDROME
}

\author{
DEVENDRA R. DESHMUKH ${ }^{a}$, GAYATRI D. DESHMUKH ${ }^{b}$, THOMAS C. SHOPE ${ }^{a}$ and NORMAN S. RADIN ${ }^{b}$ \\ ${ }^{a}$ Department of Pediatrics and Communicable Diseases and ${ }^{b}$ Mental Health Research Institute and Department of Biological Chemistry, \\ University of Michigan, Ann Arbor, MI 48109 (U.S.A.)
}

(Received May 5th, 1983)

Key words: Fatty acid; Reye's syndrome; Serum ammonia; Influenza; Encephalopathy; (Ferret)

Recent studies have indicated that viral infections, aspirin treatment and hyperammonemia are associated with Reye's syndrome. It has also been reported that free fatty acids in serum and total lipids in the liver of Reye's syndrome patients are elevated during illness. The role of the lipid changes in the development of the disorder cannot be optimally studied in human patients, because infection and aspirin ingestion occur prior to the earliest symptoms of Reye's syndrome. Effects of influenza B infection, aspirin treatment and hyperammonemia on the level of free fatty acids, total lipids and triacylglycerols in serum and liver of an animal model of Reye's syndrome are reported here. Hyperammonemia was produced in young, male ferrets either by feeding them small amounts of an arginine-deficient diet after overnight fasting or by an intraperitoneal injection of jackbcan urease. The ferret model resembled Reye's syndrome in developing increased levels of individual and total serum free fatty acids, liver triacylglycerol and total lipids. The results also indicate that influenza infection or aspirin treatment, or both, while increasing the severity of encephalopathy in the deficient ferrets, did not cause a significant change in the level of serum free fatty acids. Other results suggest that elevation of serum ammonia, serum free fatty acid or liver lipids, either singly or in various combinations, does not provide conditions that can explain the rapidly developing encephalopathy in the arginine-deficient ferrets.

\section{Introduction}

Reye's syndrome is a potentially fatal childhood disorder of unknown etiology that occurs following a viral illness, such as influenza or chickenpox [1,2]. Early symptoms of Reye's syndrome include persistent vomiting and behavioural changes, and it may lead progressively to coma and death in advanced cases [3]. Clinical features of Reye's syndrome include hyperammonemia, elevated serum transaminases, increased prothrombin time and normal levels of serum bilirubin [3]. In addition, fatty infiltration of viscera and liver mitochondrial abnormalities are described.

Free fatty acids are increased in the serum of Reye's syndrome patients during illness and return to normal after recovery [4-8]. Continuous infusion of sodium octanoate - a short-chain fatty acid salt - into rabbits produced many of the clinical, biochemical and pathologic changes commonly found in Reye's syndrome patients [9]. These studies suggested that the elevated free fatty acids may be partly responsible for the coma, hepatocyte injury and increased intracranial pressure in this syndrome $[4,10-11]$. But whether the increase in serum free fatty acids occurs before or after liver injury in Reye's syndrome is not known. The role of elevated free fatty acids and their interaction with other etiologic agents (influenza, ammonia, etc.) are difficult to study in patients because viral infection and liver injury occur well before Reye's syndrome is diagnosed. An animal 
model may be useful for such studies. Ferrets are well suited for animal model studies because, unlike other laboratory animals, they are susceptible to human influenza infections. They also develop hyperammonemia soon after eating a diet deficient in arginine [12,13]. Recently, we have shown that influenza B infection, aspirin treatment and the arginine-deficient diet act in combination to produce Reye's syndrome-like disorders in young, male ferrets [12]. Many of the clinical, metabolic and histopathologic disorders commonly found in Reye's syndrome patients were reproduced in this animal model.

This study was undertaken to investigate whether there is a similar pattern of changes in free fatty acids in the animal model and, if so, to examine the relationship between hyperammonemia, encephalopathy and free fatty acids. Non-toxic doses of aspirin and virus were used. Hyperammonemia was produced in the young, male ferrets by feeding an arginine-deficient diet or by intraperitoneal injection of urease.

\section{Materials and Methods}

Animals. 8-week-old, male, sable-coated ferrets (Mustela putorius furo L), vaccinated for canine distemper, were purchased from Marshall Research Laboratory, North Rose, NY. They were kept in groups of three or four, in cages with grid flooring, in an isolation room with controlled light and temperature.

Diets. Water and cat chow were provided ad libitum except when specified diets were given. A synthetic diet containing free amino acids was prepared as described previously [14], with minor modifications. Corn oil was used instead of turkey fat. Commercial vitamin and salt mixtures (ICN Pharmaceuticals, Cleveland, $\mathrm{OH}$ ) were used. An arginine-deficient diet was prepared by substituting alanine for an isonitrogenous amount of arginine.

Infection. Ferrets were infected with influenza B by inoculating $0.5 \mathrm{ml}$ of virus (Georgia/101/79) into each nostril during light diethyl ether anesthesia. The viral titre was $10^{6}$ egg ID $_{50}$ per $\mathrm{ml}$. Racks of cages with infected ferrets were well separated from those of non-infected controls.

Aspirin treatment. Acetylsalicylic acid (Sigma
Chemical Co., St. Louis) was suspended in water, neutralized with $1 \mathrm{~N}$ sodium hydroxide using a $\mathrm{pH}$ meter, and given by feeding tube $(50 \mathrm{mg} / \mathrm{kg}$, twice daily).

Experimental design. Ferrets were divided into ten groups of at least four animals each designated as follows (Table I): 1, chow-fed control; 2, synthetic diet; 3, influenza; 4, aspirin; 5, influenza and aspirin; 6, arginine-deficient diet; 7, influenza and arginine-deficient diet; 8, aspirin and arginine-deficient diet; 9, influenza, aspirin and arginine-deficient diet; 10 , urease injection. Those in groups 3, 5, 7 and 9 were infected at 10:00 a.m. on the first day. Aspirin treatment of the ferrets in groups 4, 5, 8 and 9 was started in the evening of the first day. On the third day at 1:00 p.m., food was removed from all the cages. On the fourth day at 9:00 a.m., cat chow was given to the ferrets in group $1,3,4,5$ and 10 , synthetic diet was given to those in group 2 and arginine-deficient diet was given to those in groups 6-9. At 9:30 a.m., the ferrets of group 10 were injected intraperitoneally with 600 I.U. $/ \mathrm{kg}$ of jackbean urease (Sigma Chemical Co., St. Louis). At 12:00 noon food was removed from groups 1-9. At 12:30 p.m. 3-ml blood samples were collected from comatose or lightly anesthetized animals by heart puncture. Serum was separated and stored at $-20^{\circ} \mathrm{C}$. Ferrets were killed at 4:00 p.m., their livers were quickly removed and frozen in pentane that was surrounded by dry ice, then stored at $-70^{\circ} \mathrm{C}$. Ammonia determinations were done immediately after separating the serum [15].

Lipid analysis. Lipids in serum and liver were extracted with hexane/isopropanol $(3: 2)$ and processed for determination of free fatty acids and triacylglycerol [16-19]. Total lipids were determined gravimetrically after washing the lipid extract with concentrated aqueous sodium sulphate to remove non-lipids [19]. The free fatty acids were isolated and then converted to their methyl esters $[17,20]$. Methyl esters were purified by thin-layer chromatography and analyzed by gas-liquid chromatography with a chromatograph equipped with a flame ionization detector and a glass column $(6$ foot $\times 2 \mathrm{~mm}$ ) packed with Ultra-pak high efficiency $15 \%$ Silar-10c (Applied Science, State College, PA) on Gas Chrom R. The temperature was programmed from 180 to $220^{\circ} \mathrm{C}$ at $2^{\circ} \mathrm{C} / \mathrm{min}$. 
Initial temperature $\left(180^{\circ} \mathrm{C}\right)$ was maintained for 2 min. Components were identified by comparison with methyl ester standards. The areas under peaks were determined with an electronic integrator in duplicate runs.

Student's $t$-test was used to calculate the statistical significance. $P$ values less than 0.05 were considered significant.

\section{Results and Discussion}

Preliminary experiments demonstrated that ferrets fed either cat chow or the synthetic diet for a week gained weight at similar rates and appeared healthy. There were no significant differences in the activities of serum aspartate aminotransferase (EC 2.6.1.1), alanine aminotransferase (EC 2.6.1.2) or ornithine carbamoyltransferase (EC 2.1.3.3) or in the levels of serum ammonia or total bilirubin between the two groups (groups 1 and 2).

The effects of diet, influenza virus and aspirin treatment, either alone or in various combinations, on serum free fatty acids levels are shown in Table I. Those fed arginine-deficient diet (group 6) had an about 15-fold increase in serum ammonia levels as compared with chow-fed controls (group 1) and became sick (prostration followed by convulsions and coma) $2 \mathrm{~h}$ after ingesting the deficient diet. Although urease-injected ferrets (group 10) had a 30-fold increase in serum ammonia levels, they did not become sick during the period of observation $(7 \mathrm{~h})$. This suggests that mere elevation of serum ammonia is not primarily responsible for the encephalopathy.

Ferrets in both high-ammonia groups (groups 6 and 10) showed a large increase in serum free fatty acids compared to the chow-fed controls. Those fed the synthetic diet (group 2) also had elevated serum free fatty acids (over 5-fold) as compared with chow-fed controls, but did not develop hyperammonemia or encephalopathy. In urease-injected (group 10), ammonia is produced by the breakdown of urea whereas in the deficient ferrets (groups 6-9) it is caused by the decreased availability of arginine for detoxification of ammonia by the urea cycle. Since the elevation of ammonia levels in the urease-injected group probably precedes other metabolic alterations, it may possibly have caused the observed increases in serum free fatty acids. However, since there was no significant difference in the high free fatty acids levels of the group fed arginine-deficient diet (group 6), which had elevated ammonia levels, and the synthetic diet (group 2), which did not, the relationship between ammonia and free fatty acids appears not to be obligatory. Elevations of serum free fatty acids in both of these groups as compared with chow-fed controls must be due to dif-

\section{TABLE I}

EFFECTS OF VARIOUS POTENTIAL ETIOLOGIC FACTORS OF REYE'S SYNDROME, ALONE OR IN COMBINATIONS, ON FREE FATTY ACIDS AND AMMONIA LEVELS IN FERRET SERUM

Results are expressed as mean \pm S.E. of four or more experiments. Asterisks indicate statistically significant difference $(P<0.05)$ as compared with chow-fed controls.

\begin{tabular}{|c|c|c|c|}
\hline Group & $\begin{array}{l}\text { Free fatty acids } \\
(\mu \mathrm{g} / \mathrm{ml})\end{array}$ & $\begin{array}{l}\text { Ammonia } \\
(\mu \mathrm{g} / 100 \mathrm{ml})\end{array}$ & Observation \\
\hline 1. Chow-fed control ${ }^{a}$ & $57 \pm 4.5$ & $294 \pm 21$ & - \\
\hline 2. Synthetic diet & $335 \pm 6.2 *$ & $231 \pm 40$ & - \\
\hline 3. Influenza infection ${ }^{a}$ & $55 \pm 8.5$ & $333 \pm 24$ & \\
\hline 4. Aspirin treatment ${ }^{a}$ & $59 \pm 7.4$ & $286 \pm 27$ & - \\
\hline 5. Influenza and aspirin & $34 \pm 14$ & $334 \pm 18$ & - \\
\hline 6. Arginine-deficient diet & $348 \pm 10 *$ & $4220 \pm 572 *$ & Sick \\
\hline 7. Influenza and arginine-deficient diet & $220 \pm 31 *$ & $4660 \pm 324 *$ & Sick \\
\hline 8. Aspirin and arginine-deficient diet & $183 \pm 41 *$ & $5600 \pm 800^{*}$ & Sick \\
\hline \multicolumn{4}{|l|}{ 9. Influenza, aspirin and } \\
\hline arginine-deficient diet & $205 \pm 28 *$ & $4760 \pm 265 *$ & Sick \\
\hline 10. Urease injection ${ }^{a}$ & $271 \pm 39 *$ & $9180 \pm 850^{*}$ & - \\
\hline
\end{tabular}

\footnotetext{
a Ferrets were fed Purina cat chow.
} 
ferences in the synthetic and chow diets other than their arginine content. Whatever that dietary factory may be, it provides a substantial elevation in serum free fatty acids that mimics that found in Reye's syndrome patients, and thus provides a means of examining the relation of such elevations to other changes accompanying illness in the model.

According to Morris and Rogers [14], synthetic diet may be absorbed faster than normal chow diet, since digestion is not required. This would produce a high level of amino acids in the serum and a high amount of deamination in the liver. The ketogenic amino acids may possibly be the source of high free fatty acids levels in the synthetic and arginine-deficient diet-fed groups. Purina cat chow contained about $8 \%$ of animal fat whereas the synthetic and arginine-deficient diets contained $25 \%$ of corn oil. This difference may also contribute for the observed differences in the serum free fatty acids levels between the synthetic or arginine-deficient group and chow-fed control.

There was no significant difference in levels of serum free fatty acids between groups fed the deficient (groups 6-9) and supplemented diets (group 2). All of the deficient ferrets were sick and hyperammonemic whereas the supplemented ferrets appeared healthy and had normal ammonia levels. Thus, although the sickness is associated with both elevated ammonia and serum free fatty acids levels (in the deficient diet group), elevated serum free fatty acids alone (in the synthetic diet group) was not associated with sickness. Our results unfortunately did not determine whether the sickness can also occur in hyperammonemic ferrets with normal levels of serum free fatty acids. That the severity of illness is not closely associated with the level of serum free fatty acids in hyperammonemic ferrets is indicated in comparisons of groups 6 and 9. Although the serum ammonia levels in these two groups were not significantly different, a much more severe illness was associated with moderately decreased serum free fatty acids levels in the deficient group treated with aspirin and influenza virus as compared with the group treated with arginine-deficient diet alone (groups 7-9 vs 6).

Influenza infection alone (group 3 ) did not cause significant changes in serum free fatty acids compared with the chow-fed controls. Influenzainfected ferrets fed the arginine-deficient diet (group 7) had moderately lower serum free fatty acids levels than those treated with the argininedeficient diet alone (group 6). These results are consistent with a report that influenza infections in humans did not cause significant increases in serum free fatty acids [21]. In the ferret studies, influenza infection alone also did not cause signifi-

\section{TABLE II}

EFFECTS OF VARIOUS POTENTIAL ETIOLOGIC FACTORS OF REYE'S SYNDROME, ALONE OR IN COMBINATION, ON MAJOR FREE FATTY ACID LEVELS IN FERRET SERUM

The fatty acid abbreviations show the chain length and number of double bonds in the acid. Results are expressed as mean \pm S.E. of at least three experiments. Asterisks indicate statistically significant difference as compared with chow-fed controls $(P<0.05)$.

\begin{tabular}{|c|c|c|c|c|c|}
\hline \multirow[t]{2}{*}{$\overline{\text { Fatty acid }}$} & \multicolumn{5}{|c|}{ Concentration of free fatty acids $(\mu \mathrm{g} / \mathrm{ml})$} \\
\hline & $\begin{array}{l}\text { Chow-fed } \\
\text { control }\end{array}$ & $\begin{array}{l}\text { Arginine- } \\
\text { deficient } \\
\text { diet }\end{array}$ & $\begin{array}{l}\text { Influenza, } \\
\text { aspirin and } \\
\text { arginine-deficient diet }\end{array}$ & $\begin{array}{l}\text { Synthetic } \\
\text { diet }\end{array}$ & $\begin{array}{l}\text { Urease } \\
\text { injections }\end{array}$ \\
\hline $14: 0$ & $2.2 \pm 0.23$ & $4.6 \pm 0.7^{*}$ & $2.8 \pm 0.32$ & $6.5 \pm 0.16^{*}$ & $5.6 \pm 1.2 *$ \\
\hline $16: 0$ & $14.8 \pm 0.80$ & $84.0 \pm 4.2 *$ & $55.7 \pm 2.9^{*}$ & $87.5 \pm 2.7^{*}$ & $67.1 \pm 6.7 *$ \\
\hline $16: 1$ & $1.7 \pm 0.22$ & $13.6 \pm 1.1^{*}$ & $7.0 \pm 1.1^{*}$ & $15.9 \pm 0.4^{*}$ & $10.9 \pm 3.1 *$ \\
\hline $18: 0$ & $9.1 \pm 0.90$ & $47.3 \pm 3.8 *$ & $33.2 \pm 4.7^{*}$ & $43.6 \pm 1.8^{*}$ & $43.7 \pm 2.0^{*}$ \\
\hline $18: 1$ & $15.7 \pm 0.90$ & $158.0 \pm 2.4 *$ & $91.6 \pm 6.1 *$ & $130.0 \pm 1.8 *$ & $100.0 \pm 12.2 *$ \\
\hline $18: 2$ & $7.5 \pm 1.1$ & $55.7 \pm 1.5^{*}$ & $22.3 \pm 0.5^{*}$ & $47.0 \pm 3.5 *$ & $30.0 \pm 5.0^{*}$ \\
\hline $20: 4$ & $1.3 \pm 0.07$ & $3.6 \pm 1.5^{*}$ & $2.2 \pm 0.15^{*}$ & $1.8 \pm 0.28$ & $1.1 \pm 0.1$ \\
\hline Total & $53.3 \pm 2.90$ & $363.0 \pm 9.5^{*}$ & $215.0 \pm 10.5^{*}$ & $332.0 \pm 3.2 *$ & $258.0 \pm 29.0^{*}$ \\
\hline
\end{tabular}


cant changes in serum ammonia levels. These ferrets did not develop encephalopathy or other obvious signs of illness, other than fever (rectal temperature, $103-105^{\circ} \mathrm{F}$ ).

Aspirin treatment of infected (group 5) or noninfected (group 4) ferrets did not cause significant changes in serum ammonia or serum free fatty acids levels as compared with chow-fed controls. Animals in these groups did not develop encephalopathy or obvious signs of illness during the period of observation.

Gas-liquid chromatography of serum free fatty acids was done only with those groups in which large increases in the concentrations of serum free fatty acids were noted. Only the major components of the serum free fatty acids pool are shown in Table II. Significant increases in the saturated and unsaturated free fatty acids were found in groups fed either the synthetic or deficient diets and also in the urease-injected as compared with chow-fed controls. However, the percent distribution of the individual free fatty acids was not increased significantly, except for the 18:1 component ( $40 \%$ as compared with $29 \%$ ). Urease-injected ferrets also had a similar increase in the percent distribution of the $18: 1$ component. The percent distributions of the $14: 0$ and $20: 4 \mathrm{com}$ ponents were decreased in the deficient and synthetic groups (groups 6 and 2) as compared with chow-fed controls. It has been reported that in Reye's syndrome patients individual and total serum free fatty acids were elevated during the illness [4]. In this study, serum free fatty acids and ammonia were determined in blood samples taken immediately after the deficient animals became sick (shortly after feeding). Free fatty acids analysis of samples taken at various time intervals may give a broader picture of the free fatty acids profiles and their relation to serum ammonia levels in ferrets.

Previous studies showed that ferrets fed the deficient diet develop increased levels of liver lipids as compared with the chow-fed controls [12]. Ferrets infected with influenza $B$ virus and/or treated with aspirin prior to treatment with arginine-deficient diet also had significant increases in liver lipids as compared with those on cat chow (Ref. 12 and Table III). Parallel increases in liver triacylglycerol were found (Table III). Similar

\section{TABLE III}

EFFECTS OF VARIOUS POTENTIAL ETIOLOGIC FACTORS OF REYE'S SYNDROME ON LIVER LIPIDS IN FERRETS

Results are expressed as mean $\pm S$.E. of at least four experiments. Asterisks indicate statistically significant difference as compared with chow-fed controls $(P<0.05)$.

\begin{tabular}{lll}
\hline Group & $\begin{array}{l}\text { Total lipids } \\
(\mathrm{mg} / \mathrm{g})\end{array}$ & $\begin{array}{l}\text { Triacylglycerol } \\
(\mathrm{mg} / \mathrm{g})\end{array}$ \\
\hline Chow-fed control & $26 \pm 2$ & $13.0 \pm 0.7$ \\
Synthetic diet & $78 \pm 5.4^{*}$ & $24.8 \pm 1.7^{*}$ \\
Arginine-deficient diet & $59 \pm 6.1^{*}$ & $20.2 \pm 1.8^{*}$ \\
$\begin{array}{l}\text { Infection, aspirin and } \\
\quad \text { arginine-deficient diet }\end{array}$ & $76 \pm 4.5^{*}$ & $23.7 \pm 1.1^{*}$ \\
Urease injection & $66 \pm 2.0^{*}$ & $18.0 \pm 0.6^{*}$ \\
\hline
\end{tabular}

changes in total lipids and triacylglycerol of liver were found in the synthetic diet group. Urease injection also resulted in increased levels of total liver lipids and triglycerides.

In conclusion, the ferret model resembled Reye's syndrome in developing increased levels of individual and total serum free fatty acids, liver triacylglycerol and total lipids. As with the serum free fatty acids, the lipid changes appear to be attributable to properties of the synthetic diet other than the arginine content, as shown by the similarities of these changes in the deficient and arginine-supplemented groups. Ketogenic amino acids may also contribute for the increased liver lipids and triacylglycerol in the synthetic and arginine-deficient diet groups, because the ketogenic amino acids are rapidly converted to fatty acids, which not only enter the plasma but also are stored in the liver as triglycerides and other lipids.

Although hyperammonemia, lipidosis and encephalopathy are often associated, their relationship is not clear. The above experiments with ferrets suggest that elevations of serum ammonia, serum free fatty acids or liver lipid levels, or combinations of these factors, are not sufficient to precipitate the development of encephalopthy. Other factors that might possibly influence the development of encephalopathy include the site of ammonia formation and the nature of the free fatty acids that were not measured in this study (short-chain fatty acids, for example; see Refs. 7 and 22). The ferret model may be useful for ex- 
amining additional factors that may help to precipitate the encephalopathy.

\section{Acknowledgements}

We thank Dr. H.F. Maassab for providing influenza B virus. This work was supported, in part, by funds from the Biomedical Research Council, University of Michigan and by a grant from the National Institutes of Health, NS 03192.

\section{References}

1 Linemann, C.C., Shea, L., Kauffman, C.A., Shiff, A.M., Partin, J.C. and Shubert, W.K. (1974) Lancet ii, 179-182

2 Corey, L., Ruben, R.J., Hattwick, M.A.W., Noble, G.A. and Cassidy, E. (1976) Am. J. Med. 61, 615-625

3 Reye, R.D.K., Morgan, A. and Baral, J. (1963) Lancet 2, 249-252

4 Ogburn, P.L., Jr., Sharp, H., Lloyd-Still, J.D., Johnson, S.B. and Holman, R.T. (1982) Proc. Natl. Acad. Sci. U.S.A. 79, 908-911

5 Pollack, J.D., Cramblett, H.A., Flynn, D. and Clark, D. (1975) in Reye's Syndrome (Pollack, J.D., ed.), pp. 227-243, Grune and Stratton. New York

6 Ogburn, P.L. Jr. (1976) South. Med. J. 69, 632-633

7 Mamunes, P., De Vries, G., Miller, H. and David, R.B. (1974) Pediatr. Res. 8, 436
8 Brown, R.E., Madge, G.E., Trauner, D.A. and David, R.B. (1972) VA Med. Mon. 99, 622-626

9 Trauner, D.A. (1982) Pediatr. Res. 16, 950-953

10 Partin, J.C., Schubert, W.K. and Partin, J.S. (1971) N. Eng. J. Med. 285, 1339-1345

11 Mamunes, P., De Vries, G.H., Miller, C.D. and David, R.B. (1975) in Reye's Syndrome (Pollack, J.D., ed.), pp. 245-254, Grune and Stratton, New York

12 Deshmukh, D.R., Maassab, H.F. and Mason, M. (1982) Proc. Natl. Acad. Sci. U.S.A. 79, 7557-7560

13 Deshmukh, D.R., Kao, W., Mason. M., Maassab, H.F. and Baublis, J.V. (1982) Enzyme 27, 52-57

14 Morris, J.G. and Rogers, Q.R. (1978) J. Nutr. 108, 1944-1953

15 Monzac, A., Ehrlich, G.E. and Seegmiller, J.E. (1965) J. Lab. Clin. Med. 66, 526-531

16 Hara, A. and Radin, N.S. (1978) Anal. Biochem. 90, 420-426

17 Radin, N.S., Deshmukh, G.D., Selvam, R. and Hospattankar, A.V. (1982) Biochim. Biophys. Acta. 713, 474-478

18 Selvam, R. and Radin, N.S. (1981) Anal. Biochem. 112, 338-345

19 Radin, N.S. (1981) Methods Enzymol. 72, 5-7

20 Radin, N.S., Hajra, A.K. and Akahori, Y. (1960) J. Lipid Res. 1, 250-251

21 Gallin, J.L., Kaye, D. and O'Leary, W. (1969) N. Eng. J. Med. 281, 1081-1086

22 Trauner, D.A., Nyhan, W.L. and Sweetman, L. (1975) Neurology 25, 296-298 